ARTICLE

\title{
Stabilization of a molecular water oxidation catalyst on a dye-sensitized photoanode by a pyridyl anchor
}

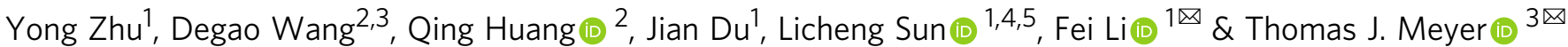

Understanding and controlling the properties of water-splitting assemblies in dye-sensitized photoelectrosynthesis cells is a key to the exploitation of their properties. We demonstrate here that, following surface loading of a $\left[\mathrm{Ru}(\mathrm{bpy})_{3}\right]^{2+}$ (bpy $=2,2^{\prime}$-bipyridine) chromophore on nanoparticle electrodes, addition of the molecular catalysts, $\mathrm{Ru}(\mathrm{bda})(\mathrm{L})_{2}$ (bda $=2,2^{\prime}$ bipyridine-6,6'-dicarboxylate) with phosphonate or pyridyl sites for water oxidation, gives surfaces with a 5:1 chromophore to catalyst ratio. Addition of the surface-bound phosphonate derivatives with $\mathrm{L}=4$-pyridyl phosphonic acid or diethyl 3-(pyridin-4-yloxy)decyl-phosphonic acid, leads to well-defined surfaces but, following oxidation to Ru(III), they undergo facile, on-surface dimerization to give surface-bound, oxo-bridged dimers. The dimers have a diminished reactivity toward water oxidation compared to related monomers in solution. By contrast, immobilization of the Ru-bda catalyst on $\mathrm{TiO}_{2}$ with the $4,4^{\prime}$-dipyridyl anchoring ligand can maintain the monomeric structure of catalyst and gives relatively stable photoanodes with photocurrents that reach to $1.7 \mathrm{~mA} \mathrm{~cm}^{-2}$ with an optimized, applied bias photonto-current efficiency of $1.5 \%$.

\footnotetext{
${ }^{1}$ State Key Laboratory of Fine Chemicals, Dalian University of Technology, Dalian 116024, China. ${ }^{2}$ Engineering Laboratory of Advanced Energy Materials, Ningbo Institute of Industrial Technology, Chinese Academy of Sciences, Ningbo, Zhejiang 315201, China. ${ }^{3}$ Department of Chemistry, University of North Carolina at Chapel Hill, Chapel Hill, NC 27599, USA. ${ }^{4}$ Department of Chemistry, School of Engineering Sciences in Chemistry, Biotechnology and Health, KTH Royal Institute of Technology, Stockholm 10044, Sweden. ${ }^{5}$ Center of Artificial Photosynthesis for Solar Fuels, School of Science, Westlake University,

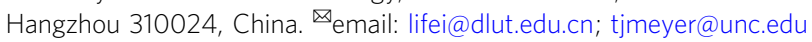


$\mathrm{n}$ solar powered water splitting, water oxidation is a mechanistic bottleneck ${ }^{1}$. The emergence of molecular water oxidation catalysts (WOCs) has provided an opportunity to mimic the oxygen-evolving complex (OEC) of photosystem II in nature ${ }^{2,3}$. In one approach, the dye-sensitized photoelectrosynthesis cell (DSPEC) $)^{4-6}$, a molecular chromophore and catalyst are immobilized on wide bandgap, n-type semiconductors, such as fluorine-doped tin oxide (FTO), with a mesoporous $\mathrm{TiO}_{2}$ layer. Water oxidation is trigged by sequential absorption of four photons with the accumulation of oxidative equivalents at a catalyst. Complexes of the type, $\mathrm{Ru}(\mathrm{bda})(\mathrm{L})_{2}$ (bda $=2,2^{\prime}$-bipyridine- $6,6^{\prime}$-dicarboxylate) with $\mathrm{L}$ a pyridyl ligand, have been shown to be efficient catalysts for homogenous or heterogeneous water oxidation with both favorable kinetics and low overpotentials for water oxidation ${ }^{7,8}$. Although the catalytic mechanism for Ru-bda water oxidation has been well studied in solution, there is less insight on electrode surfaces.

A notable difference between homogeneous and heterogenized catalysts is the surface anchoring group. Apart from providing a basis for surface immobilization, the bridging ligand can have a significant impact on electron and hole transfer through a metal oxide/molecular interface ${ }^{9,10}$. In a DSPEC, electronic coupling through a bridging ligand enables efficient electron injection from a photo-excited dye into the conduction band of the semiconductor. By contrast, a surface catalyst for water oxidation, requires long-lived charge separation and the accumulation of four oxidative equivalents with a different distance behavior between activation and back electron transfer. Although a variety of anchors have been explored in dye-sensitized solar cells (DSSCs) $)^{11}$, suitable candidates for DSPEC photoanodes are dictated by the requirements for electron transfer and hydrolytic stability. To date, phosphonic and carboxylic acids have been the most widely used anchoring groups, especially phosphonates because of their hydrolytic stability on $\mathrm{TiO}_{2}{ }^{4,12-19}$. The acid anchors prefer to attach on $\mathrm{TiO}_{2}$ by covalent bonding with the hydroxyl groups (Brønsted acid sites) on the surface. Though stable in organic media, the stability of covalent binding in aqueous solution is largely dependent on external $\mathrm{pH}$ values because of potential hydrolysis at $\mathrm{pH}>5$. This undesirable hydrolysis results in the detachment of chromophore or catalyst from the metal oxide surface.

In comparison, pyridine is known to adsorb over $\mathrm{TiO}_{2}$ surface by coordination with the exposed $\mathrm{Ti}$ atoms (Lewis acid sites). Given the different mechanisms between phosphonate and pyridine binding, pyridine anchored $\mathrm{TiO}_{2}$ was expected to be more stable against hydrolysis in near-neutral aqueous solutions. In the literature, catalysis with pyridine as an anchor for surface-bound catalysts is scarcely reported. Sakai and Ozawa et al. ${ }^{20}$ have constructed a photoanode with a pyridine-functionalized $[\mathrm{Ru}$ $\left.(\text { bpy })_{3}\right]^{2+}$ (bpy $=2,2^{\prime}$-bipyridine) complex as the chromophore immobilized on $\mathrm{TiO}_{2}$ film. This photoanode was examined for the PEC oxidation of EDTA. Comparison with analogous phosphonate-derivatized $\left[\mathrm{Ru}(\mathrm{bpy})_{3}\right]^{2+}$ complexes demonstrates improved surface stability in aqueous solution at $\mathrm{pH}$ 5. Another example was also reported by the same group, where a pyridinederivatized platinum(II) porphyrin was used as an electrocatalyst for water reduction ${ }^{21}$.

In this study, we demonstrate, an important dependence for a surface-bound catalyst for water oxidation on surface anchoring groups. The results described here show that upon oxidation, a Ru-bda catalyst with phosphonate binding, can rapidly form surface-bound $\mu$-oxo-bridged dimers which have a greatly decreased reactivity toward water oxidation. We also find that the dimerization process can effectively be inhibited by replacing phosphonate acid binding groups with a pyridine anchor. The impact of the structural change on the performance of dyesensitized photoanodes is remarkable. By utilizing pyridine binding, the photocurrent is enhanced by an order of magnitude giving a maximum solar photon-to-current efficiency for water oxidation of $1.5 \%$.

\section{Results}

Preparation of electrodes. In the research described here, photoanodes were prepared by co-adsorption of a phosphonatederivatized tris(2,2'-bipyridine)ruthenium(II) dichloride salt of $\left(\mathbf{R u P}^{2+}\right)$ as the chromophore with pyridyl-derivatized $\mathrm{Ru}(\mathrm{bda})$ $\left(4,4^{\prime} \text {-bpy }\right)_{2}\left(4,4^{\prime}\right.$-bpy $=4,4^{\prime}$-bipyridine, 1$)$ catalysts on the surfaces of a post-treated $\mathrm{TiO}_{2}$ layer on FTO (Fig. 1a). Complex 1 was synthesized in a one-step reaction between $\mathrm{Ru}(\mathrm{bda})(\mathrm{DMSO})_{2}$ the $4,4^{\prime}$-bpy in a procedure that is far more facile than for phosphonate $^{22}$ or silane linking (Supporting Information) $)^{17,23}$. The electrodes consisted of $6 \mu \mathrm{m}$ layers of $20 \mathrm{~nm}$ nanoparticles of $\mathrm{TiO}_{2}$ on FTO substrates (Supplementary Fig. 5). Chromophore and catalyst were loaded on $\mathrm{TiO}_{2}$ by soaking the slide in methanol solutions of $\mathbf{R u P}^{2+}(1 \mathrm{mM})$ and catalyst $(1 \mathrm{mM})$ in sequence. As noted below, spectrophotometric analysis of the electrodes reveals that, under the conditions used for surface loading, the ratio of chromophore to catalyst was $\sim 5: 1$ with the external surface dominated by the chromophore ${ }^{24,25}$. As a way to demonstrate and modify the surface anchoring group, the phosphonate-bound catalysts, $\mathrm{Ru}(\mathrm{bda})\left(4-\mathrm{pyPO}_{3} \mathrm{H}\right)_{2}\left(4-\mathrm{pyPO}_{3} \mathrm{H}\right.$ is 4-pyridyl phosphonic acid) (2), and $\mathrm{Ru}(\mathrm{bda})(4-\mathrm{pyO}$ $\left.\left(\mathrm{CH}_{2} \mathrm{CH}_{2}\right)_{5} \mathrm{PO}_{3} \mathrm{H}\right)_{2}$ (4-pyO $\left(\mathrm{CH}_{2} \mathrm{CH}_{2}\right)_{5} \mathrm{PO}_{3} \mathrm{H}$ is diethyl 3-(pyridin-4-yloxy)decyl-phosphonic acid) $(3)^{16}$ were also prepared (Fig. 1b).

The electrochemical properties of co-derivatized films of the catalysts and $\mathbf{R u P}{ }^{2+}$ on $\mathrm{TiO}_{2}$ were investigated by cyclic voltammetry. In a pH 5.8 acetate buffer solution, the electrode $\mathrm{TiO}_{2} \mid-\left(\mathbf{R u P}^{2+}\right)_{5}, \mathbf{1}$ includes a $2 \mathrm{e}^{-}, \mathrm{Ru}^{\mathrm{IV}}-\mathrm{OH}^{+} / \mathrm{Ru}^{\mathrm{II}}-\mathrm{OH}_{2}{ }^{2+}$ couple at $E_{1 / 2} \sim 0.7 \mathrm{~V}$ vs. NHE (Fig. 2) 26,27 . A catalytic current for water oxidation appeared at $1.1-1.2 \mathrm{~V}$ with a significant current enhancement appearing at a higher potential due to the onset wave for the $\mathbf{R u P} \mathbf{P}^{3+/ 2+}$ couple at $E_{1 / 2} \sim 1.25 \mathrm{~V}$.

Based on an analysis of peak currents and inductively coupled plasma emission measurements ${ }^{14,28}$, surface loadings of
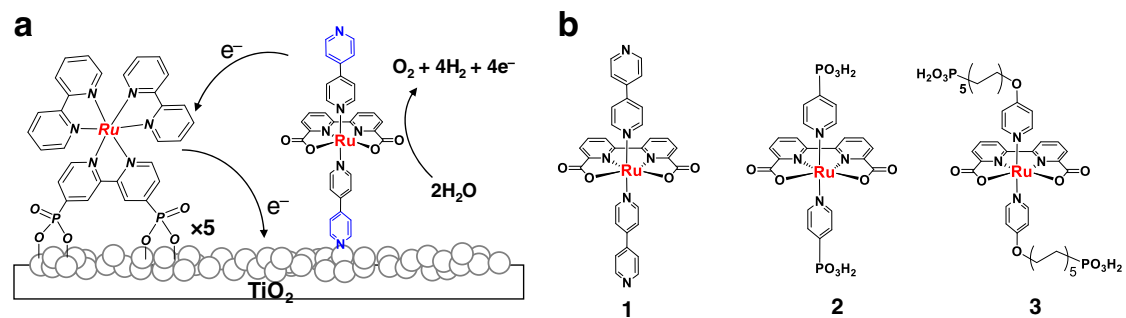

Fig. 1 Photoanode schematic and catalysts structure. a A surface loading scheme for cross-surface electron transfer between RuP2+ and catalyst 1 coloaded on a photoanode. $\mathbf{b}$ Structures of the catalysts used in the study. 


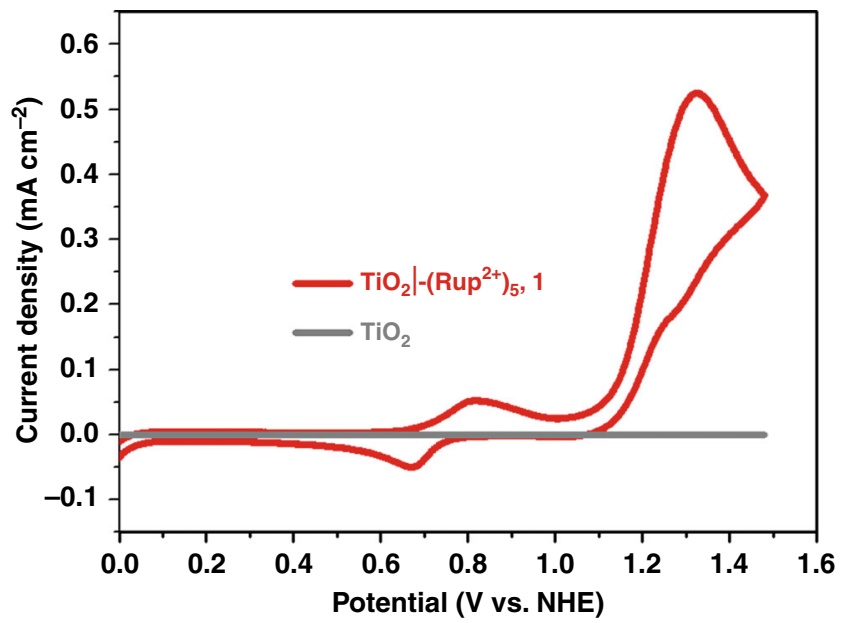

Fig. 2 Cyclic voltammetry. Cyclic voltammogram for $\mathrm{TiO}_{2}$ and $\mathrm{TiO}_{2} \mathrm{I}^{-}$ $\left(\mathbf{R u P}^{2+}\right)_{5}, \mathbf{1}$ in $0.1 \mathrm{M}$ acetic acid/acetate buffer at $\mathrm{pH} 5.8$ in $0.5 \mathrm{M} \mathrm{NaClO}_{4}$ at a scan rate $10 \mathrm{mV} \mathrm{s}^{-1}$.

chromophore and catalyst on the photoanode were $1.2 \times 10^{-8}$ $\mathrm{mol} \mathrm{cm}{ }^{-2}$ for $\mathbf{1}$ and $6 \times 10^{-8} \mathrm{~mol} \mathrm{~cm}^{-2}$ for $\mathbf{R u P}^{2+}$, respectively, consistent with a chromophore to catalyst ratio of $5: 1$ (Supplementary Fig. 6a, b). A related CV behavior was observed for the electrode $\mathrm{TiO}_{2} \mid-\left(\mathbf{R u P}^{2+}\right)_{5}, \mathbf{2}$ with a surface loading of $6 \times$ $10^{-8} \mathrm{~mol} \mathrm{~cm}^{-2}$ for $\mathbf{R u P}^{2+}$ and $1.3 \times 10^{-8} \mathrm{~mol} \mathrm{~cm}^{-2}$ for 2 (Supplementary Fig. 6c), which are comparable to that for $\mathrm{TiO}_{2} \mid-\left(\mathbf{R u P}^{2+}\right)_{5}, \mathbf{1}$. The corresponding redox potential for the $\mathrm{Ru}^{\mathrm{IV}}-\mathrm{OH}^{+} / \mathrm{Ru}^{\mathrm{II}}-\mathrm{OH}_{2}{ }^{2+}$ couple in $\mathrm{TiO}_{2} \mid-\left(\mathbf{R u P}^{2+}\right)_{5}, 2$ was $E_{1 / 2} \sim 0.65 \mathrm{~V}$ with a catalytic onset at $1.1-1.2 \mathrm{~V}$ (Supplementary Fig. 7). The surface loading for $\mathrm{TiO}_{2} \mid-\left(\mathbf{R u P}^{2+}\right)_{5}, 3$ was $1.2 \times 10^{-8}$ mol cm${ }^{-2}$ for 3 (Supplementary Fig. 6d) with $E_{1 / 2} \sim 0.65 \mathrm{~V}$ (Supplementary Fig. 8). However, as noted below, for both of the phosphonate catalysts, CV scans to the higher oxidation states result in dimerization of the catalyst with a significant decrease in catalytic ability.

Water splitting. Photoelectrochemical measurements and water splitting were investigated for $\mathrm{TiO}_{2} \mid-\left(\mathbf{R u P}^{2+}\right)_{5}, \mathbf{1}$ in a $\mathrm{pH} 5.8$ acetate buffer in $0.5 \mathrm{M} \mathrm{NaClO}_{4}$. In these experiments the cathode was a $\mathrm{Pt}$ mesh counter electrode with $\mathrm{Ag} / \mathrm{AgCl}$ as the reference electrode. The light source was simulated sunlight (300 W Xenon arc lamp at a light intensity of $100 \mathrm{~mA} \mathrm{~cm}^{-2}$ equipped with a 400-nm cut-off filter) ${ }^{4}$. As shown by photoelectrochemical linear scan voltammograms (LSV), in Fig. 3a, visible light irradiation of $\mathrm{TiO}_{2} \mid-\left(\mathbf{R u P}^{2+}\right)_{5}, \mathbf{1}$ resulted in a rapid increase in photocurrent at an onset potential of $-0.2 \mathrm{~V}$ vs. NHE which reached a maximum value of $1.7 \mathrm{~mA} \mathrm{~cm}^{-2}$ at $0.1 \mathrm{~V}$ vs. NHE. Consistent results were obtained over extended periods by using chopped light irradiation at $30 \mathrm{~s}$ intervals with a constant bias (Fig. 3b). Conversely, for the assembly $\mathrm{TiO}_{2} \mid-\left(\mathbf{R u P}^{2+}\right)_{5}, \mathbf{2}$, the maximum current was reduced by a factor of 12 to $140 \mu \mathrm{A} \mathrm{cm}^{-2}$, Fig. 3a.

As shown in Table 1, the photocurrent for $\mathrm{TiO}_{2} \mid-\left(\mathbf{R u P} \mathbf{P}^{2+}\right)_{5}, \mathbf{1}$ exceeds values for other dye-sensitized photoanodes under similar conditions. An incident photo-to-current efficiency (IPCE) of $25 \%$ was obtained for $\mathrm{TiO}_{2} \mid-\left(\mathbf{R u P} \mathbf{P}^{2+}\right)_{5}, \mathbf{1}$, at the visible absorption maximum for $\mathbf{R u P}^{2+}$ (Fig. 3c), a value that is comparable to the highest IPCE values that have been documented for photoanodes of this kind (Table 1) ${ }^{16}$. Compared to other catalyst design structures, the results here are notable because of the ease of electrode preparation and cell performance $^{29,30}$. Preparation of the electrode involves a simple electrode fabrication step with a doctor-blade-coated electrode followed by addition of the catalyst ${ }^{17,31}$.

After a 2-h irradiation period for $\mathrm{TiO}_{2} \mid-\left(\mathbf{R u P}^{2+}\right)_{5}, \mathbf{1}$ at $0.2 \mathrm{~V}$ vs. $\mathrm{NHE}$, the photocurrent had fallen to $0.8 \mathrm{~mA} \mathrm{~cm}^{-2}$, which is also impressive compared to related literature examples (Supplementary Fig. 9). During this process, $6.24 \mu \mathrm{mol}$ evolved oxygen was quantified by gas chromatography with $2.66 \mathrm{C}$ charges passed through the photoanode, corresponding to a faradaic efficiency of over $90 \%$ and a TON of 520 . Hydrogen at the cathode was also monitored by gas chromatography and shown to be produced in the 2:1 ratio consistent with water oxidation (Supplementary Fig. 10).

An additional parameter of note in characterizing the electrodes is the applied bias photon-to-current efficiency (ABPE) which has not been systematically investigated for electrodes of this type ${ }^{32}$. As shown in Fig. 3d, the optimal ABPE for $\mathrm{TiO}_{2} \mid-$ $\left(\mathbf{R u P}^{2+}\right)_{5}, \mathbf{1}$ was $1.5 \%$ at $0.3 \mathrm{~V}$ vs. NHE based the photocurrents from a 1 sun, AM $1.5 \mathrm{G}$ light source. The values reported here are lower than values reported for the visible-light-absorbing semiconductor photoanodes $\mathrm{BiVO}_{4}$ and $\mathrm{Ta}_{3} \mathrm{~N}_{5}(2.5 \%$ at $0.56 \mathrm{~V}$ for $\mathrm{BiVO}_{4}{ }^{33}$ and $2.5 \%$ at $0.9 \mathrm{~V}$ for $\mathrm{Ta}_{3} \mathrm{~N}_{5}{ }^{34}$ ). However, they appear at relatively low applied potentials because of the more negative conduction band potential of $\mathrm{TiO}_{2}$ compared to the narrow bandgap semiconductors which is of advantage in biasfree water splitting with an external photocathode ${ }^{35,36}$.

Inhibition of back electron transfer. The results from the PEC water oxidation experiments point to an important role for the bridging ligand. To further understand the effect of the anchoring ligand, photoelectrochemical impedance spectroscopy measurements (PEIS) were conducted. Nyquist plots, and an appropriate equivalent circuit diagram, are shown in Fig. 4a. A typical PEIS spectrum for DSPEC exhibits a semicircle in the Nyquist plots, arising from charge recombination resistance $\left(\mathrm{R}_{\text {rec }}\right)$ at the interface between the $\mathrm{TiO}_{2} \mid$ chromophore and the catalyst ${ }^{31,37}$. Given the comparable loadings of the chromophores on the electrodes, the semicircles in the PEIS measurements directly reflect the capability of the catalyst to inhibit back electron transfer. As shown in Fig. 4a, the Nyquist plot for $\mathrm{TiO}_{2} \mid-\mathbf{R u P} \mathbf{P}^{2+}, \mathbf{1}(348 \Omega)$ includes a larger semicircle radius compared for $\mathrm{TiO}_{2} \mid-\mathbf{R u} \mathbf{P}^{2+}, \mathbf{2}$ $(155 \Omega)$. The electron recombination rate constant, $k_{\mathrm{r}}$, can be estimated from, $k_{\mathrm{r}}=1 / \mathrm{C} \cdot \mathrm{R}_{\mathrm{rec}}$, with the corresponding $K_{\mathrm{r}}$ values for photoanodes from catalyst 1 and 2 of 56 and $146 \mathrm{~s}^{-1}$ consistent with a role for the pyridyl bridging ligand in reducing back electron transfer.

Given these results, a Ru-bda derived catalyst, decorated with decyl-phosphonic acid, $\mathrm{Ru}(\mathrm{bda})\left(4-\mathrm{pyO}\left(\mathrm{CH}_{2} \mathrm{CH}_{2}\right)_{5} \mathrm{PO}_{3} \mathrm{H}\right)_{2} \quad$ (3), was also co-loaded with $\mathbf{R u P}^{2+}$ on $\mathrm{TiO}_{2}$ (Fig. 1) ${ }^{16}$. Due to the long alkyl spacer, the catalyst center in the assembly is predictably well-separated from the oxide surface, minimizing back electron transfer ${ }^{38,39}$. As expected, a large semicircle $(1453 \Omega)$ in the high frequency region of PEIS Nyquist plot was observed for $\mathrm{TiO}_{2} \mid-$ $\mathbf{R u P}^{2+}, \mathbf{3}$, consistent with a much smaller recombination rate, $35 \mathrm{~s}^{-1}$, compared to $56 \mathrm{~s}^{-1}$ for $\mathbf{1}$ and $146 \mathrm{~s}^{-1}$ for 2 . Even with this kinetic advantage, the PEC experiment showed that $\mathrm{TiO}_{2} \mid-$ $\left(\mathbf{R u P}^{2+}\right)_{5}, \mathbf{3}$ produced a photocurrent at $0.8 \mathrm{~mA} \mathrm{~cm}^{-2}$, only onehalf that for $\mathrm{TiO}_{2} \mid-\mathbf{R u} \mathbf{P}^{2+}, \mathbf{1}$ under the same conditions (Fig. 4b).

Dimerization. During the PEC experiments, $\mathrm{TiO}_{2} \mid-\left(\mathbf{R u} \mathbf{P}^{2+}\right)_{5}, \mathbf{2}$ (Fig. 5a) and $\mathrm{TiO}_{2} \mid-\left(\mathbf{R u P}^{2+}\right)_{5}, \mathbf{3}$ (Supplementary Fig. 11) underwent a rapid color change from dark red to green with the appearance of strong absorption bands at $700 \mathrm{~nm}$. Appearance of the new absorption feature, as noted above, was consistent with the results of previous studies and the appearance of surface- 

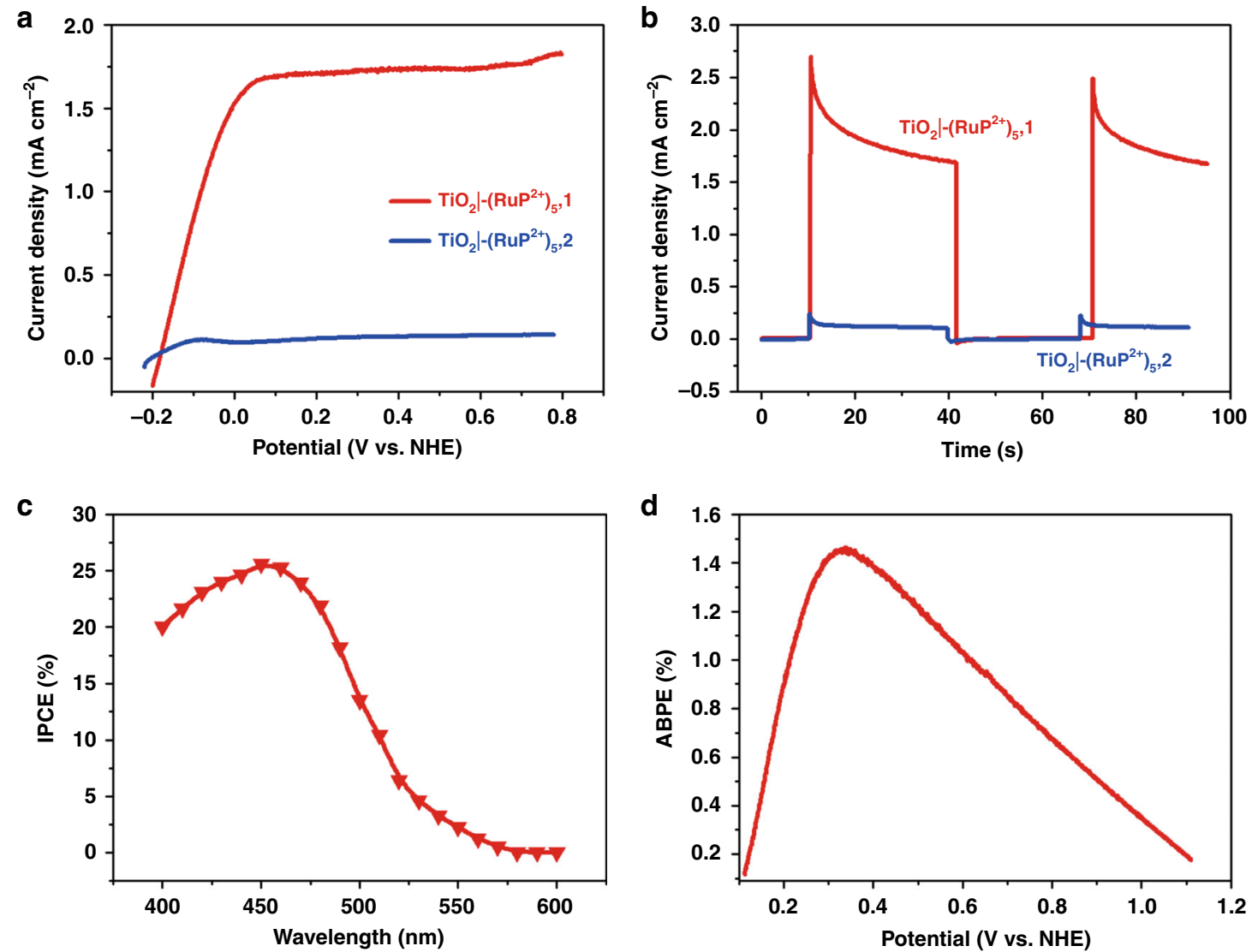

Fig. 3 Photocurrent and efficiencies of photoanodes. a Potential dependence of photocurrents for $\mathrm{TiO}_{2} \mid-\left(\mathbf{R u P} \mathbf{P}^{2+}\right)_{5}, \mathbf{1}$ and $\mathrm{TiO}_{2} \mid-\left(\mathbf{R u P} \mathbf{P}^{2+}\right)_{5}, \mathbf{2}$ with illumination above $400 \mathrm{~nm}$ at $100 \mathrm{~mW} \mathrm{~cm}^{-2}$ at pH 5.8 in a $0.1-\mathrm{M}$ acetate buffer containing $0.5 \mathrm{M} \mathrm{NaClO}_{4}$. b As in a, current density-time traces for TiO $\mathrm{I}^{-}$ $\left(\mathbf{R u P}^{2+}\right)_{5}, \mathbf{1}$ and $\mathrm{TiO}_{2} \mathrm{l}-\left(\mathbf{R u P} \mathbf{P}^{2+}\right)_{5}, \mathbf{2}$ at a constant bias of $0.2 \mathrm{~V}$ vs. NHE. c Incident photon-to-current efficiencies $(\mathrm{IPCEs})$ for TiO $\mathrm{O}_{2}-(\mathbf{R u P} 2+)_{5}, \mathbf{1}$ at $0.2 \mathrm{~V}$ vs. NHE. d Applied bias photon-to-current efficiencies (ABPEs) for $\mathrm{TiO}_{2} \mathrm{l}-\left(\mathbf{R u} \mathbf{P}^{2+}\right)_{5}, \mathbf{1}$ for photoelectrochemical water splitting.

Table 1 Relative efficiencies for water oxidation by DSPEC photoanodes ${ }^{\mathrm{a}}$.

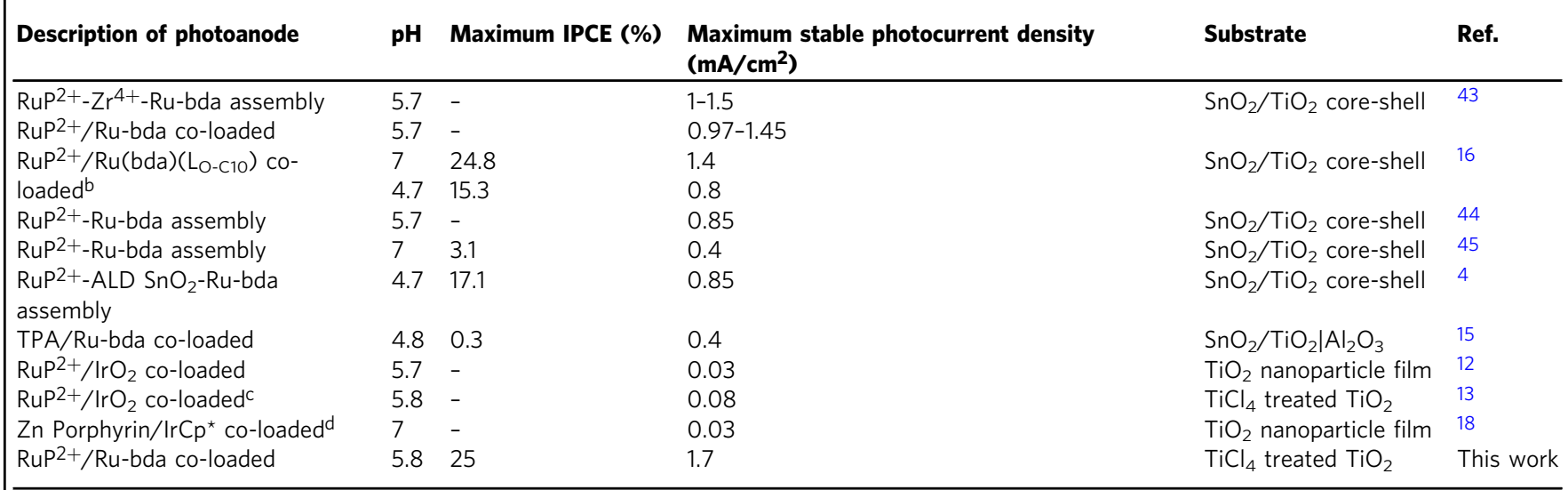

aUnless otherwise specified, simulated sunlight with a density of $100 \mathrm{~mW} \mathrm{~cm}^{-2}$ was used as the light source.

b $\mathrm{L}_{\mathrm{O}-\mathrm{C} 10}$ is diethyl 3-(pyridin-4-yloxy)decyl-phosphonic acid.

CA $150-W$ Xe lamp was used as the light source with a $410 \mathrm{~nm}$, long-pass filter and a water filter.

dAt $200 \mathrm{~mW} \mathrm{~cm}^{-2}$.

bound $\mu$-oxo bridged, binuclear ruthenium dimers as shown in Fig. 6 for $\left[\mathrm{Ru}(\mathrm{bda})\left(4-\mathrm{pyPO}_{3} \mathrm{H}\right)_{2}\right]_{2} \mathrm{O}\left(2^{\prime}\right)^{40,41}$.

The appearance of the dimer was investigated by cyclic voltammetry on nanoITO films. As shown in Fig. 4c, complete conversion from 2 to $\mathbf{2}^{\prime}$ occurred after four CV scan cycles. The redox features for $2^{\prime}$ closely resemble those reported previously for a surface-bound Ru-bda dimer with a 3-(pyridin-4-yloxy) propyl)phosphonic acid anchor ${ }^{41}$. In the $\mathrm{CV}$ there are three single-electron processes that can be assigned to the $\mathrm{Ru}^{\mathrm{II}}-\mathrm{O}-\mathrm{Ru}^{\mathrm{III}}$ / $\mathrm{Ru}^{\mathrm{III}}-\mathrm{O}-\mathrm{Ru}^{\mathrm{III}}$ couple $\left(0.73 \mathrm{~V}\right.$ vs. NHE), the $\mathrm{Ru}^{\mathrm{III}}-\mathrm{O}-\mathrm{Ru}^{\mathrm{III}} / \mathrm{Ru}^{\mathrm{III}}-\mathrm{O}$ $\mathrm{Ru}^{\mathrm{IV}}$ couple $\left(0.93 \mathrm{~V}\right.$ vs. NHE), and the $\mathrm{Ru}^{\mathrm{III}}-\mathrm{O}-\mathrm{Ru}^{\mathrm{IV}} / \mathrm{Ru}^{\mathrm{IV}}-\mathrm{O}-$ $\mathrm{Ru}^{\mathrm{IV}}$ couple (1.3 V vs. NHE).

Compared to the monomeric precursor 2 , the decrease in catalytic current for $\mathbf{2}^{\prime}$ demonstrates a reduced reactivity towards 

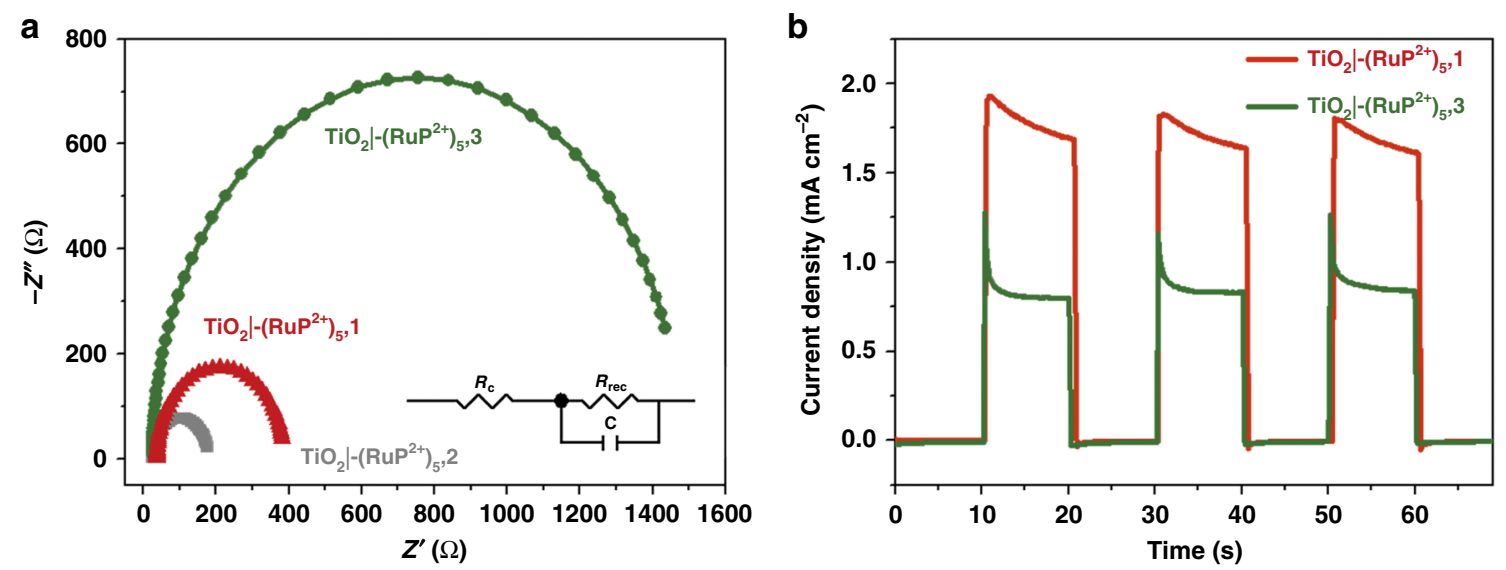

Fig. 4 Photoelectrochemical impedance spectroscopy and photocurrent of photoanodes. a PEIS Nyquist plots for $\mathrm{TiO}_{2}\left|-\left(\mathbf{R u P}^{2+}\right)_{5}, \mathbf{1}, \mathrm{TiO}_{2}\right|-\left(\mathbf{R u P}^{2+}\right)_{5}, \mathbf{2}$, and $\mathrm{TiO}_{2} \mathrm{l}-\left(\mathbf{R} \mathbf{R} \mathbf{P}^{2+}\right)_{5}, \mathbf{3}$ with $420-\mathrm{nm}$ LED illumination at an intensity of $3.5 \mathrm{~mW} \mathrm{~cm}{ }^{-2}$. Inset: the equivalent circuit used for data fitting. $\mathbf{b}$ Current densitytime traces for $\mathrm{TiO}_{2} \mathrm{I}-\left(\mathbf{R u P} \mathbf{P}^{2+}\right)_{5}, \mathbf{1}$ and $\mathrm{TiO}_{2} \mathrm{l}-\left(\mathbf{R u P} \mathbf{P}^{2+}\right)_{5}, \mathbf{3}$ at a constant bias of $0.2 \mathrm{~V}$ vs. NHE under illumination $\left(<400 \mathrm{~nm}, 100 \mathrm{~mW} \mathrm{~cm}^{-2}\right)$.
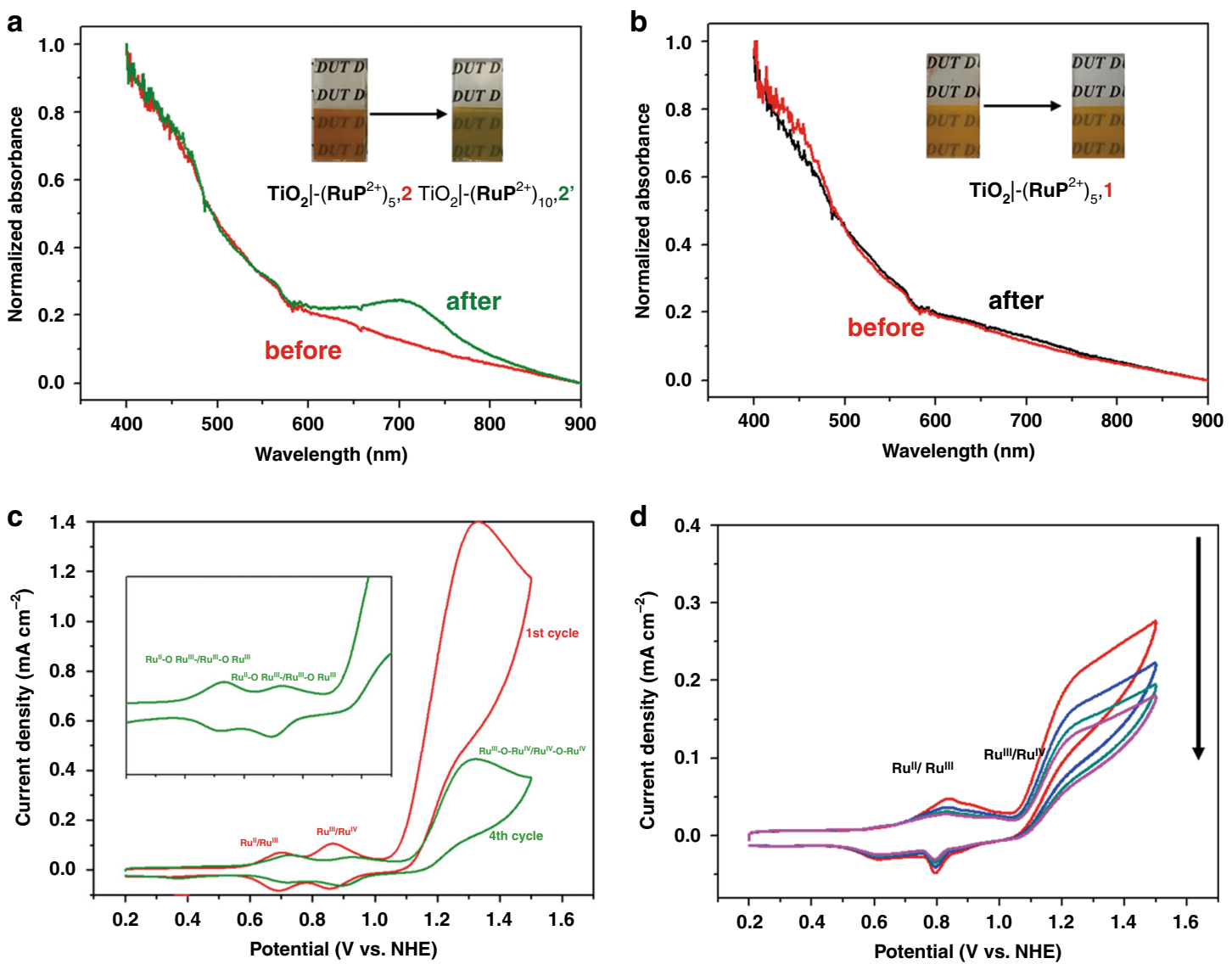

Fig. 5 UV-Vis spectral changes of photoanodes and successive cyclic voltammogram changes. UV-Vis spectral changes in acetate buffers ( $\mathrm{pH} 5.8$, $\left.0.5 \mathrm{M} \mathrm{NaClO}_{4}\right)$ at a scan rate of $10 \mathrm{mV} / \mathrm{s}$ for $\mathrm{TiO}_{2} \mid-\left(\mathbf{R u P} \mathbf{P}^{2+}\right)_{5}, \mathbf{2}(\mathbf{a})$ and $\mathrm{TiO}_{2} \mid-\left(\mathbf{R u} \mathbf{P}^{2+}\right)_{5}, \mathbf{1}$ (b) before and after $\mathrm{PEC}$ experiments. Inset: images of $\mathrm{TiO}_{2} \mid-$ $\left(\mathbf{R u P}^{2+}\right)_{5}, \mathbf{2}$ and $\mathrm{TiO}_{2} \mathrm{I}-\left(\mathbf{R u P}{ }^{2+}\right)_{5}, \mathbf{1}$ before (left) and after the PEC experiments (right). c Successive cyclic voltammograms for nanolTO $\mathbf{- 2} \mathbf{2}$ with the insert showing results for a fourth CV cycle. (d) As in c, but for nanolTO|-1, with the decrease in current due to slow desoption of $\mathbf{1}$ from the electrode.

water oxidation with low photocurrents for $\mathrm{TiO}_{2} \mid-\left(\mathbf{R u P} \mathbf{P}^{2+}\right)_{5}, \mathbf{2}^{\prime}$ $\left(40 \mu \mathrm{A} \mathrm{cm}^{-2}\right.$, Supplementary Fig. 12). A similar phenomenon was also observed for $\mathrm{TiO}_{2} \mid-\left(\mathbf{R u P} \mathbf{P}^{2+}\right)_{5}, \mathbf{3}$ (Supplementary Fig. 13). In contrast to $\mathbf{2}$ and $\mathbf{3}$, catalyst $\mathbf{1}$, with bridging pyridyl anchoring groups resulted in no color change during the photoelectrolysis period (Fig. 5b) with stable waveforms recorded for multiple CV scans (Fig. 5d), consistent with a stable monomer structure on the electrode. The color change and dimer formation also occurred for films of $\mathrm{TiO}_{2} \mid-\left(\mathbf{R u} \mathbf{P}^{2+}\right)_{5}, \mathbf{2}$ and $\mathrm{TiO}_{2} \mid-\left(\mathbf{R u} \mathbf{P}^{2+}\right)_{5}, \mathbf{3}$ in air, while $\mathrm{TiO}_{2} \mid-\left(\mathbf{R u P} \mathbf{P}^{2+}\right)_{5}, \mathbf{1}$ was relatively stable for weeks.

As noted above, the $\mathrm{CV}$ results are consistent with the formation of $\mu$-oxo-bridged, $\mathrm{Ru}^{\mathrm{III}}-\mathrm{O}-\mathrm{Ru}^{\mathrm{III}}$ dimers following oxidation of $\mathrm{Ru}^{\mathrm{II}}$ to $\mathrm{Ru}^{\mathrm{III}}$ in the catalyst ${ }^{40,41}$. Reducing the amounts of catalyst $\mathbf{2}$ or $\mathbf{3}$ that were surface loaded, was not sufficient to avoid formation of "green dimers" as shown by CV scans. In this case, the difference in surface stability between the 

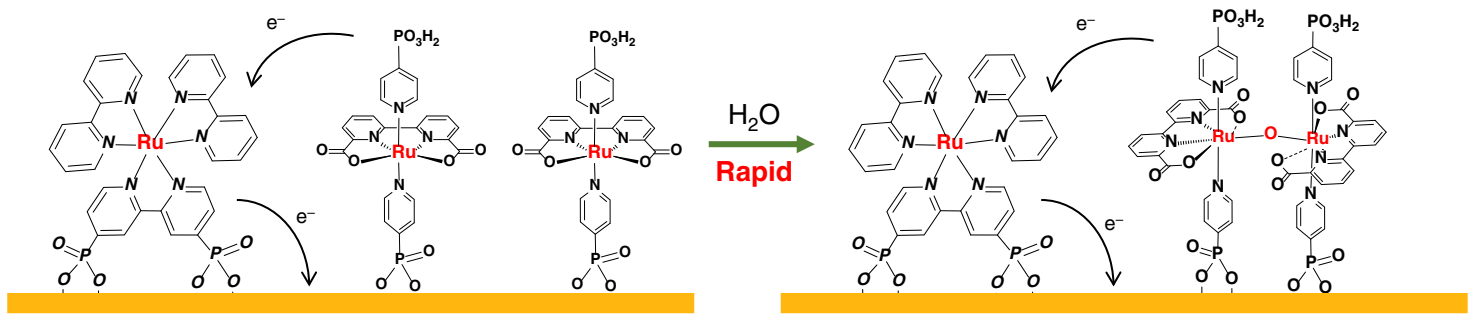

green dimer

Fig. 6 Green dimer. Dimerization of catalyst $\mathbf{2}$ on the electrode surface.

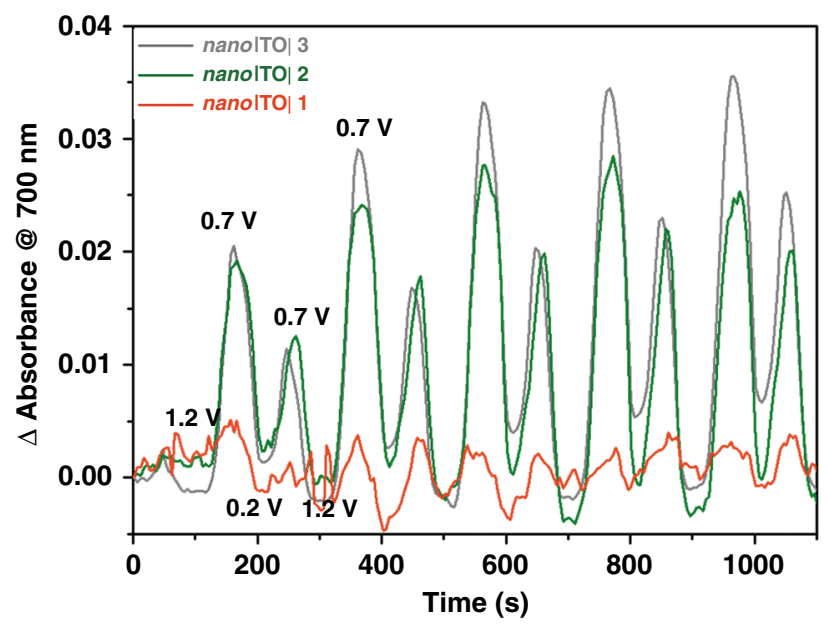

Fig. 7 Spectroelectrochemical of photoanodes. Absorption spectral changes at $700 \mathrm{~nm}$ during cyclic voltammetry scans for nanolTO|-1, 2, and 3 at pH 5.8 in a $0.1 \mathrm{M}$ acetate buffers containing $0.5 \mathrm{M} \mathrm{NaClO}_{4}$ at a scan rate $10 \mathrm{mV} / \mathrm{s}$.

phosphine and pyridyl ligands is significant, and presumably arises from rapid phosphonate loss from the surface in weakly acidic solutions.

The surface assemblies were also investigated spectroelectrochemical. Figure 7 shows the dynamic changes that occur at 700 $\mathrm{nm}$ following successive CV scans for nanoITO|-1, 2 and $\mathbf{3}$ in the dark. In these experiments, the potential was scanned in the anodic direction at $10 \mathrm{mV} \mathrm{s}^{-1}$ from 0.2 to $1.2 \mathrm{~V}$ and then back to $0.2 \mathrm{~V}$ with spectra recorded every $5 \mathrm{~s}$. For nanoITO|-2, after the first positive half-scan from 0.2 to $1.2 \mathrm{~V}$, the absorption at $700 \mathrm{~nm}$ appears periodically at each half-scan, finally reaching a maximum at the peak potential for the $\mathrm{Ru}^{\mathrm{II}}-\mathrm{O}-\mathrm{Ru}^{\mathrm{III}} / \mathrm{Ru}^{\mathrm{III}}-\mathrm{O}-$ $\mathrm{Ru}^{\mathrm{III}}$ couple. The data are consistent with the appearance of the $\mathrm{Ru}^{\mathrm{III}}-\mathrm{O}-\mathrm{Ru}^{\mathrm{III}}$ form of the dimer as an active intermediate in the catalytic cycle. Similar behavior was exhibited by catalyst $\mathbf{3}$ as shown in Fig. 7. By contrast, there was no spectrophotometric evidence, for dimerization by $\mathbf{1}$, Fig. 7, presumably because of more stable pyridine-to-surface bonding.

The dimerization of the phosphonic acid-modified Mn catalyst on mesoporous $\mathrm{TiO}_{2}$ has been previously reported by Reisner et. al. ${ }^{42}$. The lability of immobilized $\mathbf{1}, \mathbf{2}$, and 3 were evaluated by catalyst desorption from a $\mathrm{pH} 5.8$ acetate buffer containing $2 \%$ sodium ascorbate. Experimental results in Supplementary Fig. 14 reveal that catalysts $\mathbf{2}$ and $\mathbf{3}$ decorated with phosphonate anchor are prone to detach from the electrode surface with desorption rate constants $k_{\text {des }}$ of $270 \mathrm{~s}^{-1}$ for 2 and $63 \mathrm{~s}^{-1}$ for 3 , while catalyst 1 decorated with pyridine anchor is much more stable on the surface $\left(k_{\text {des }}(\mathbf{1})=1.4 \mathrm{~s}^{-1}\right)$. Given the dynamic $\mathrm{TiO}_{2} \mid$ catalyst interface, the formation of surface-bound "green dimer" is assumed to be a result of desorption of oxidized phosphonate- modified catalysts under the conditions of PEC experiments, followed by dimerization and re-adsorption within mesoporous $\mathrm{TiO}_{2}$.

\section{Discussion}

We have described here a straightforward procedure for the preparation of photoelectrodes for water oxidation in aqueous solutions with added acetate buffers. The surfaces of nanoparticle electrodes sensitized by a phosphonate-derivatized, $\mathrm{Ru}(\mathrm{II}) \mathrm{bpy}$ based chromophores, were added a water oxidation catalyst based on derivatives of the $\mathrm{Ru}(\mathrm{bda})(\mathrm{L})_{2}$ with the axial ligands $4,4^{\prime}$ bipyridine (1), 4-pyPO $\mathrm{P}_{3} \mathrm{H}$ (2), and 4-pyO $\left(\mathrm{CH}_{2} \mathrm{CH}_{2}\right)_{5} \mathrm{PO}_{3} \mathrm{H}(3)$. In forming the catalytic surfaces, the chelate diphosphonate linkages of the chromophore result in complete surface coverage with subsequent addition of the mono-dentate pyridyl or phosphonatederivatized catalysts to give final surface coverages of chromophore to catalyst of $5: 1$.

Cyclic voltammetry and UV-Vis spectroscopy measurements in $0.1 \mathrm{M}$ acetate buffers in $0.5 \mathrm{M} \mathrm{NaClO}_{4}$ show that oxidation of the surface-bound catalysts results in oxidation from $\mathrm{Ru}(\mathrm{II})$ to $\mathrm{Ru}$ (IV). Multiple scan voltammograms for the phosphonate derivatives were consistent with dimerization of the phosphonatederivatized catalysts to O-bridged catalyst dimers. The latter were far less reactive toward water oxidation but are retained on the oxide surfaces. In a relative sense, the $4,4^{\prime}$-bpy electrode described here is impressive for water oxidation. The incident phototo-current efficiency for $\mathrm{TiO}_{2} \mid-\left(\mathbf{R u P}^{2+}\right)_{5}, \mathbf{1}$, is comparable to the highest IPCE values documented for photoanodes of this kind (Table 1) at the visible absorption maximum for $\mathbf{R u P}^{2+}$ (Fig. 1c), with a maximum solar efficiency of $1.5 \%$. Our results offer an important message for molecular level assembly design. Recognizing the importance of anchoring groups in determining the catalytic active species on metal oxide surface adds a new approach to the rational tuning of hybrid interfaces for DSPEC applications.

\section{Methods}

Preparation of photoanode. Ca. $6 \mu \mathrm{m}$ thickness $\mathrm{TiO}_{2}$ films were coated on FTO glass by the doctor-blade method. The $\mathrm{TiO}_{2}$ paste was doctor-bladed onto a clean FTO substrate followed by a sintering process at $120^{\circ} \mathrm{C}$ for $30 \mathrm{~min}, 450^{\circ} \mathrm{C}$ for $1 \mathrm{~h}$ After cooling to room temperature, the electrodes were immersed into a $50-\mathrm{mM}$ aqueous $\mathrm{TiCl}_{4}$ solution for $1 \mathrm{~h}$ at $70^{\circ} \mathrm{C}$ before calcination at $450{ }^{\circ} \mathrm{C}$ for $1 \mathrm{~h}$. The FTO supported $\mathrm{TiO}_{2}$ film was sensitized by soaking the slide in a methanol solution containing RuP ( $1 \mathrm{mM}$ ) for $1 \mathrm{~h}$, followed by soaking in another methanol solution containing complex $1(1 \mathrm{mM})$ or complex 2 or $3(1 \mathrm{mM})$ for $1 \mathrm{~h}$. The sensitized electrode was dried in dark at room temperature after rinsing by methanol. The transparent conductive nanoITO thin films were prepared according to previously published methods ${ }^{16}$.

Photoelectrochemical measurements. All photoelectrochemical measurements were carried out at room temperature by using a $\mathrm{CHI} 660 \mathrm{E}$ electrochemical workstation (Shanghai Chenhua Instrument Co., LTD). The photoelectrochemical performances of photoanodes were measured with a typical three-electrode configuration with the photoanode as the working electrode, a platinum wire as the counter electrode, and saturated $\mathrm{Ag} / \mathrm{AgCl}(0.194 \mathrm{~V}$ vs. $\mathrm{NHE})$ as the reference electrode. The simulated sunlight was obtained by passing light from a $300-\mathrm{W}$ 
Xenon arc lamp (CEAULIGHT) equipped with a 400-nm filter or an AM1.5 G filter, the power intensity of the incident light was calibrated to $100 \mathrm{~mW} / \mathrm{cm}^{2}$ using a THORLABS S401C power meter.

The incident photon to current efficiency (IPCE) at each wavelength was determined by using illumination from a 300-W Xenon arc lamp (CEAULIGHT), The monochromatic light was produced using a monochromator (Beijing 7-star optical instruments-7ISW75) with a 10-nm bandpass. The light intensity $\left(P_{\lambda}\right)$ at each wavelength $(\lambda)$ was determined with a THORLABS S120VC power meter. The IPCE value was calculated using the equation:

$$
\operatorname{IPCE}(\%)=\frac{1240 \times\left(J_{\text {light }}-J_{\text {dark }}\right)}{\lambda \times P_{\lambda}} \times 100 \%
$$

The applied bias photo-to-current efficiency (ABPE) was calculated based on the current-potential curves under 1 sun, AM1.5 G illumination,

$$
\operatorname{ABPE}(\%)=\frac{\left(J_{\text {light }}-J_{\text {dark }}\right) \times\left(1.23-V_{\mathrm{RHE}}\right)}{P_{\text {light }}} \times 100 \%
$$

With $V_{\mathrm{RHE}}$ is the applied potential versus RHE, $J_{\text {light }}$ and $J_{\text {dark }}$ the measured photocurrent and dark current, respectively. $P_{\text {light }}$ is the power density of the lamp, AM $1.5 \mathrm{G}\left(100 \mathrm{~mW} \mathrm{~cm}^{-2}\right)$.

Determination of Faradaic efficiency. The amounts of oxygen and hydrogen evolution were determined by gas chromatography. Before the measurement, the sealed electrolytic cell was degassed with Argon for $15 \mathrm{~min}$ to remove residual air. The amount of oxygen and hydrogen evolution after $2 \mathrm{~h}$ of electrolysis at $0.2 \mathrm{~V}$ vs. NHE was measured. The Faradaic efficiency was calculated according to the integrated charge $(\mathrm{Q})$ passed and the amount of $\mathrm{O}_{2}$ evolved using the equation:

$$
\eta(\%)=\frac{96485 \times n_{\mathrm{O}_{2}} \times 4}{\mathrm{Q}} \times 100 \%
$$

Photoelectrochemical impedance spectroscopy. PEIS was measured with typical three-electrode under an intensity of $3.5 \mathrm{~mW} \mathrm{~cm}^{-2} 420$-nm LED illumination at pH 5.8 in $0.1 \mathrm{M}$ acetic acid/acetate buffer containing $0.5 \mathrm{M} \mathrm{NaClO}_{4}$. The PEIS measurements were scanned from $1 \times 10^{3}$ to $1 \mathrm{~Hz}$. PEIS experiments were carried out in galvanostatic mode at open-circuit. The current perturbation was set to $5 \mu \mathrm{A}$.

\section{Data availability}

The data that support the findings of this study available in this published Article and its Supplementary Information, or from the corresponding authors upon reasonable request

Received: 11 December 2019; Accepted: 12 August 2020;

Published online: 14 September 2020

\section{References}

1. Walter, M. G. et al. Solar water splitting cells. Chem. Rev. 110, 6446-6473 (2010).

2. Kärkäs, M. D., Verho, O., Johnston, E. V. \& Åkermark, B. Artificial photosynthesis: molecular systems for catalytic water oxidation. Chem. Rev. 114, 11863-12001 (2014).

3. Duan, L., Wang, L., Li, F., Li, F. \& Sun, L. Highly efficient bioinspired molecular ru water oxidation catalysts with negatively charged backbone ligands. Acc. Chem. Res. 48, 2084-2096 (2015).

4. Wang, D. et al. Layer-by-layer molecular assemblies for dye-sensitized photoelectrosynthesis cells prepared by atomic layer deposition. J. Am. Chem. Soc. 139, 14518-14525 (2017).

5. Ashford, D. L. et al. Molecular chromophore-catalyst assemblies for solar fuel applications. Chem. Rev. 115, 13006-13049 (2015).

6. Ding, X., Zhang, L., Wang, Y., Liu, A. \& Gao, Y. Design of photoanode-based dye-sensitized photoelectrochemical cells assembling with transition metal complexes for visible light-induced water splitting. Coord. Chem. Rev. 357, 130-143 (2018).

7. Duan, L., Fischer, A., Xu, Y. \& Sun, L. Isolated seven-coordinate Ru(IV) dimer complex with $[\mathrm{HOHOH}]-$ bridging ligand as an intermediate for catalytic water oxidation. J. Am. Chem. Soc. 131, 10397-10399 (2009).

8. Duan, L. et al. A molecular ruthenium catalyst with water-oxidation activity comparable to that of photosystem II. Nat. Chem. 4, 418-423 (2012).

9. Materna, K. L., Crabtree, R. H. \& Brudvig, G. W. Anchoring groups for photocatalytic water oxidation on metal oxide surfaces. Chem. Soc. Rev. $\mathbf{4 6}$, 6099-6110 (2017).

10. Young, K. J. et al. Light-driven water oxidation for solar fuels. Coord. Chem. Rev. 256, 2503-2520 (2012).
11. Galoppini, E. Linkers for anchoring sensitizers to semiconductor nanoparticles. Coord. Chem. Rev. 248, 1283-1297 (2004).

12. Youngblood, J. W. et al. Photoassisted overall water splitting in a visible lightabsorbing dye-sensitized photoelectrochemical cell. J. Am. Chem. Soc. 131, 926-927 (2009).

13. Zhao, Y. et al. Improving the efficiency of water splitting in dye-sensitized solar cells by using a biomimetic electron transfer mediator. Proc. Natl. Acad. Sci. USA 109, 15612-15616 (2012).

14. Vannucci, A. K. et al. Crossing the divide between homogeneous and heterogeneous catalysis in water oxidation. Proc. Natl. Acad. Sci. USA 110 20918-20922 (2013).

15. Eberhart, M. S. et al. Water photo-oxidation initiated by surface-bound organic chromophores. J. Am. Chem. Soc. 139, 16248-16255 (2017).

16. Wang, $\mathrm{D}$. et al. Interfacial deposition of $\mathrm{Ru}(\mathrm{II})$ bipyridine-dicarboxylate complexes by ligand substitution for applications in water oxidation catalysis. J. Am. Chem. Soc. 140, 719-726 (2018).

17. Gao, Y. et al. Visible light driven water splitting in a molecular device with unprecedentedly high photocurrent density. J. Am. Chem. Soc. 135, 4219-4222 (2013).

18. Moore, G. F. et al. A visible light water-splitting cell with a photoanode formed by codeposition of a high-potential porphyrin and an iridium wateroxidation catalyst. Energy Environ. Sci. 4, 2389-2392 (2011).

19. $\mathrm{Li}, \mathrm{H}$. et al. Visible light-driven water oxidation promoted by host-guest interaction between photosensitizer and catalyst with a high quantum efficiency. J. Am. Chem. Soc. 137, 4332-4335 (2015).

20. Takijiri, K., Morita, K., Nakazono, T., Sakai, K. \& Ozawa, H. Highly stable chemisorption of dyes with pyridyl anchors over TiO2: application in dyesensitized photoelectrochemical water reduction in aqueous media. Chem. Commun. 53, 3042-3045 (2017).

21. Morita, K., Takijiri, K., Sakai, K. \& Ozawa, H. A platinum porphyrin modified $\mathrm{TiO}_{2}$ electrode for photoelectrochemical hydrogen production from neutral water driven by the conduction band edge potential of $\mathrm{TiO}_{2}$. Dalton Trans. 46 , 15181-15185 (2017).

22. Gillaizeau-Gauthier, I. et al. Phosphonate-based bipyridine dyes for stable photovoltaic devices. Inorg. Chem. 40, 6073-6079 (2001).

23. Shan, B. et al. A molecular silane-derivatized $\mathrm{Ru}(\mathrm{II})$ catalyst for photoelectrochemical water oxidation. J. Am. Chem. Soc. 140, 15062-15069 (2018).

24. Ooyama, Y. et al. Dye-sensitized solar cells based on donor-acceptor $\pi$ conjugated fluorescent dyes with a pyridine ring as an electron-withdrawing anchoring group. Angew. Chem. Int. Ed. 50, 7429-7433 (2011).

25. Zhang, L. \& Cole, J. M. Anchoring groups for dye-sensitized solar cells. ACS Appl. Mater. Interfaces 7, 3427-3455 (2015).

26. Wang, D. et al. A stable dye-sensitized photoelectrosynthesis cell mediated by a $\mathrm{NiO}$ overlayer for water oxidation. Proc. Natl. Acad. Sci. USA 117, 201821687 (2019).

27. Ashford, D. L., Sherman, B. D., Binstead, R. A., Templeton, J. L. \& Meyer, T. J. Electro-assembly of a chromophore-catalyst bilayer for water oxidation and photocatalytic water splitting. Angew. Chem. Int. Ed. 54, 4778-4781 (2015).

28. Zhang, J. et al. Vertical step-growth polymerization driven by electrochemical stimuli from an electrode. Angew. Chem. Int. Ed. 57, 16698-16702 (2018).

29. Sauvage, F. et al. Dye-sensitized solar cells employing a single film of mesoporous $\mathrm{TiO}_{2}$ beads achieve power conversion efficiencies over $10 \%$. ACS Nano 4, 4420-4425 (2010).

30. O'Regan, B. \& Grätzel, M. A low-cost, high-efficiency solar cell based on dyesensitized colloidal $\mathrm{TiO}_{2}$ films. Nature 353, 737-740 (1991).

31. Xu, P., Gray, C. L., Xiao, L. \& Mallouk, T. E. Charge recombination with fractional reaction orders in water-splitting dye-sensitized photoelectrochemical cells. J. Am. Chem. Soc. 140, 11647-11654 (2018),

32. Hisatomi, T., Kubota, J. \& Domen, K. Recent advances in semiconductors for photocatalytic and photoelectrochemical water splitting. Chem. Soc. Rev. 43, $7520-7535$ (2014).

33. Tian, Z. et al. Novel black $\mathrm{BiVO}_{4} / \mathrm{TiO}_{2-x}$ photoanode with enhanced photon absorption and charge separation for efficient and stable solar water splitting. Adv. Energy Mater. 1901287, 1-8 (2019).

34. Liu, G. et al. Enabling an integrated tantalum nitride photoanode to approach the theoretical photocurrent limit for solar water splitting. Energy Environ. Sci. 9, 1327-1334 (2016).

35. Ling, Q., Huang, W., Baldwin, A. \& Jarvis, P. Chloroplast biogenesis is regulated by direct action of the ubiquitin-proteasome system. Science 338, 655-659 (2012).

36. Brillet, J. et al. Highly efficient water splitting by a dual-absorber tandem cell. Nat. Photon. 6, 824-828 (2012).

37. Eom, Y. K. et al. Thieno[3,2-b][1]benzothiophene derivative as a new $\pi$-bridge unit in $D-\pi$-a structural organic sensitizers with over $10.47 \%$ efficiency for dye-sensitized solar cells. Adv. Energy Mater. 5, 1-9 (2015).

38. Li, F. et al. Organic dye-sensitized tandem photoelectrochemical cell for light driven total water splitting. J. Am. Chem. Soc. 137, 9153-9159 (2015). 
39. Gao, Y., Zhang, L., Ding, X. \& Sun, L. Artificial photosynthesis-functional devices for light driven water splitting with photoactive anodes based on molecular catalysts. Phys. Chem. Chem. Phys. 16, 12008-12013 (2014).

40. Concepcion, J. J., Zhong, D. K., Szalda, D. J., Muckerman, J. T. \& Fujita, E. Mechanism of water oxidation by $\left[\mathrm{Ru}(\mathrm{bda})(\mathrm{L})_{2}\right]$ : the return of the 'blue dimer'. Chem. Commun. 51, 4105-4108 (2015).

41. Wang, D. et al. A molecular photoelectrode for water oxidation inspired by photosystem II. J. Am. Chem. Soc. 141, 7926-7933 (2019).

42. Rosser, T. E., Windle, C. D. \& Reisner, E. Electrocatalytic and solar-driven $\mathrm{CO}_{2}$ reduction to $\mathrm{CO}$ with a molecular manganese catalyst immobilized on mesoporous $\mathrm{TiO}_{2}$. Angew. Chem. Int. Ed. 55, 7388-7392 (2016).

43. Sherman, B. D. et al. Evaluation of chromophore and assembly design in lightdriven water splitting with a molecular water oxidation catalyst. ACS Energy Lett. 1, 231-236 (2016).

44. Sherman, B. D. et al. Light-driven water splitting by a covalently linked ruthenium-based chromophore-catalyst assembly. ACS Energy Lett. 2, 124-128 (2017).

45. Sherman, B. D. et al. Light-driven water splitting with a molecular electroassembly-based core/shell photoanode. J. Phys. Chem. Lett. 6, 3213-3217 (2015).

\section{Acknowledgements}

This work was supported by the National Natural Science Foundation of China (21872016), the LiaoNing Revitalization Talents Program (XLYC1807125), the Swedish Energy Agency, and the K \& A Wallenberg Foundation.

\section{Author contributions}

F.L., T.J.M., and L.S. supervised this project; Y.Z., D.W., Q.H., and F.L. designed the experiments; Y.Z. and J.D. prepared the electrodes, performed characterization and photoelectrochemical measurements; Y.Z., D.W., F.L., and T.J.M. wrote the manuscript.

\section{Competing interests}

The authors declare no competing interests.

\section{Additional information}

Supplementary information is available for this paper at https://doi.org/10.1038/s41467020-18417-5.

Correspondence and requests for materials should be addressed to F.L. or T.J.M.

Peer review information Nature Communications thanks the anonymous reviewers for their contribution to the peer review of this work. Peer reviewer reports are available.

Reprints and permission information is available at http://www.nature.com/reprints

Publisher's note Springer Nature remains neutral with regard to jurisdictional claims in published maps and institutional affiliations.

(c) Open Access This article is licensed under a Creative Commons Attribution 4.0 International License, which permits use, sharing, adaptation, distribution and reproduction in any medium or format, as long as you give appropriate credit to the original author(s) and the source, provide a link to the Creative Commons license, and indicate if changes were made. The images or other third party material in this article are included in the article's Creative Commons license, unless indicated otherwise in a credit line to the material. If material is not included in the article's Creative Commons license and your intended use is not permitted by statutory regulation or exceeds the permitted use, you will need to obtain permission directly from the copyright holder. To view a copy of this license, visit http://creativecommons.org/ licenses/by/4.0/.

(C) The Author(s) 2020 